\title{
Sobre dos objetos del cine: El amor y el
} miedo $^{1}$

\author{
Ángela Bonadies \\ angelabonadies@yahoo.com
}

"El miedo devora el alma"

Traducción del título original en alemán de la película Todos nos llamamos Alí, de R.W.

Fassbinder

"Ningún cordero ha salvado su piel balando" Frase extraída de la película América América de Elia Kazan

"Pero qué miedo, cada vez, el peor de los miedos. Y qué amor." Marguerite Duras en Escribir

Escribir no es simplemente el rigor mecánico de describir, por ejemplo, el devenir de un acontecimiento, anodino o sonoro, o un esbozo de su sobresalto. Es un hecho que se apega al lenguaje propio y que tiende a estar impregnado de los humores de aquellos días en que ocurrió: por un lado el hecho de estar y ver, por el otro el de traducirlo a palabras. Es una maraña que se desenreda y que a su vez se enreda, cómo no, con todas las partes de nuestro cuerpo y espíritu. De esa escena salpica algo a la escritura, una construcción de mirada que tenderá a sufrir nuestros colapsos: tranquilidad, nerviosismo, taquicardia, mareos, lagunas, rapidez, aburrimiento, duda, ansiedad, miedo; incluso una ruptura de corazón, el amor. En el texto se apreciarán los trozos, las partes, los síntomas -entre líneas. Y esto sin tener que abandonar la pasión objetiva, al contrario, aguzándola hacia la disección científica: una mirada justa sobre nuestra subjetividad, la posibilidad de pensar y sentir con ambos verbos en coro, como algunas de las películas que más conmovieron mi pensamiento durante este festival, con el poder de revolucionar las neuronas y hacer arder el cuerpo con ese flujo ácido que apunta al estómago: el miedo, y aquel otro indescriptible que no deja nada en su lugar: el amor. La pantalla tiene el don de dejarse escribir y dejarnos entrever y escuchar, a través de los listones de la celosía y la amenaza del ruido, con "atención, paciencia y violencia", tres atributos que Olvido García Valdés exige ante la poesía y, por qué no, me atrevo a decir, ante el hecho de ver y hacer cine.

\section{INVENTARIO A: Emigrantes}

A los abuelos Graciela y Juan Bautista, que hicieron el gran viaje entre esos dos objetos.

\footnotetext{
${ }^{1} 54$ Festival Internacional de Cine de Donostia-San Sebastián
} 
"El día que comprendí lo que era y cuál sería mi lugar en la sociedad, el margen, deseé ser cualquier otro, por ejemplo: un americano". Elia Kazan

Cuando llegue el momento en que mi miedo sea más grande que mi anhelo por algo bello, pondré el punto final, y no sólo a mi trabajo. R.W. Fassbinder

Este año uno de los grandes ciclos del festival fue titulado Emigrantes, películas en las que, como el nombre subraya, vimos historias de desplazados, mudados, gente que se fue de su país a buscar mejor fortuna o fortuna a secas, que se movió para cazar otras condiciones, para escapar de la guerra, las hambrunas, las epidemias, la depresión económica, la colonización política o espiritual, para estudiar, zafarse o encontrarse. Gente que, de diferentes formas, con más o menos ayuda, hizo su maleta y ahí instaló un trozo de su primera vida, para intentar arrastrarlo a la otra orilla o soltarlo cuando pesara demasiado. En algunas vimos el viaje, como en América América (1964) de Elia Kazan; en otras la estadía y la vivencia como extranjero, como en Todos nos llamamos Alí (1974) de R.W. Fassbinder. Brutales y crudas, desesperantes, ambas películas podrían funcionar en el momento actual, plantear los mismos miedos universales, con el añadido de que las fronteras de hoy son más paranoicas. La aventura de migrar sigue siendo un horizonte esperanzador cada vez más cerrado y restringido y, paradoja eterna, muy explotado y lucrativo.

América América es una épica al estilo homérico, una peregrinación hacia un lugar y un sentir, hacia la madurez de un joven que busca nacer de nuevo para borrar los pecados originales de ese viaje. Todos nos llamamos Alí, al contrario, se sitúa en un espacio geográfico y espiritual más apretado,

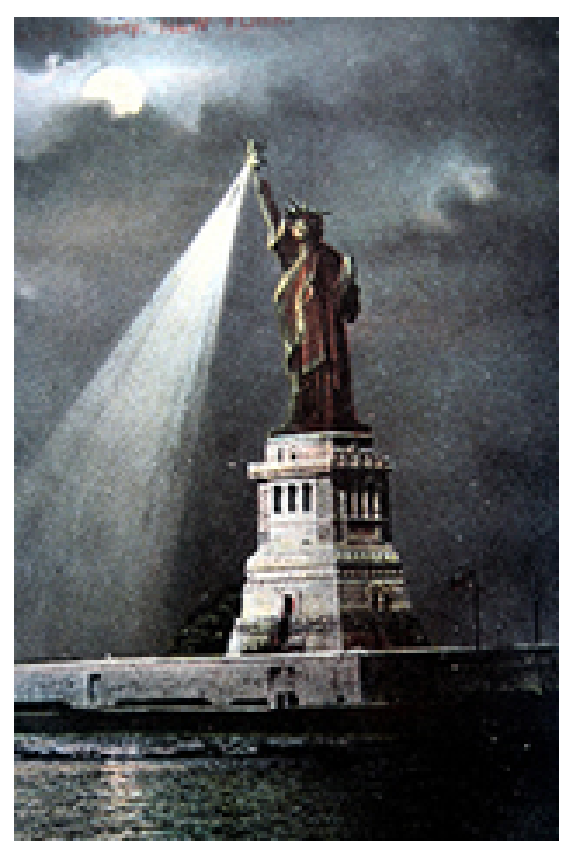

Ilustración 1 Grabado que muestra la Estatua de la Libertad menos dramático o heroico, pero no por ello menos trágico ni profundo. El viaje en América América es también la metáfora de un viaje interno, del viaje de un personaje solitario, Stavros, que quiere encontrarse a sí mismo y convertirse en hombre. Es un viaje entre pasajes y paisajes. El de Alí es más sencillo y en un sentido: práctico, de un hombre que sufre de una manera menos épica, más a ras de suelo, y a quien la luz baña con un carácter realista y colorido, menos expresionista y contrastado, como los grandes negros y blancos que golpean al atormentado joven griego que busca América. Esa América representada por Estados Unidos, país que estuvo abierto a la llegada de extranjeros a finales del siglo XIX y principios del XX: una vez que el barco anclaba en Ellis Island (la isla que se codea con la estatua de la libertad, tantos años símbolo de la entrada al nuevo continente) había que pasar un examen médico y una aprobación oficial -si eras viajero de tercera clase. Acto seguido se recibía, a cargo de un funcionario de frontera, un informal bautizo laico que convertía a los extranjeros en estadounidenses. Lo que seguía era lidiar con el país, el idioma, el trabajo y lo que hiciera falta, que no era poco. Algunas penurias las narró Chaplin en El Inmigrante (1917), con ese rictus irónico de quien hace una mueca a la desgracia.

El viaje emprendido no termina cuando se llega sano y salvo a puerto: allí casi termina la película de Kazan, en la puerta americana, y un poco después comienza la de Fassbinder y el marroquí Alí en 
Alemania: un viaje a pie por las esquinas no siempre biseladas de otro idioma, otra cultura, por sus diversas aristas. En ambas el viaje recrea esos objetos a los que nos referimos: el amor y el miedo,

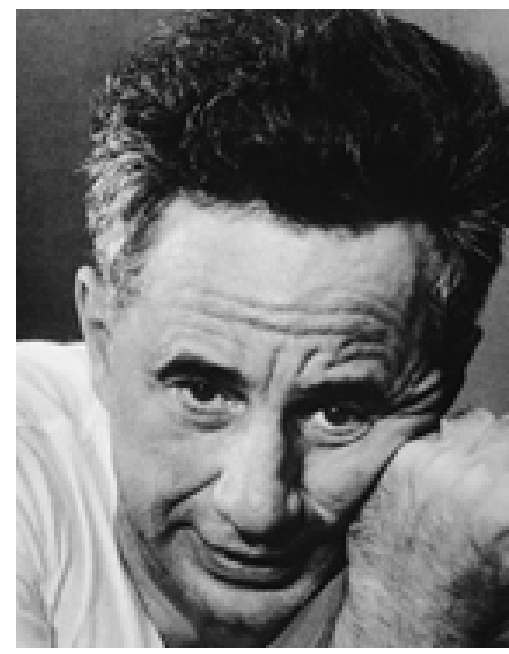

Ilustración 2 Elia Kazan que se transmutan constantemente en poder y crueldad. El cambio opera y comienza por borrar algunas señas de identidad tan fuertes como el nombre propio. Unas veces para bien, otras para mal, el inmigrante quedaba marcado: el joven griego de América América cambia su nombre como lo haría la familia del propio Elia Kazan, cuyo apellido original era Kazanjoglou, proveniente de la Anatolia griega, invadida y colonizada por los turcos durante siglos. También El Hedi Ben Salem M'Barek Mohammed Mustafa resumirá su nombre en Alí, porque todos los árabes se llaman Alí, como bien dice en la película, cuyo título ha sufrido también las marcas de la migración: traducida al francés como Todos los otros se llaman Alí (un título apegado a la antropología de la otredad), al español como Todos nos llamamos Alí (más incluyente o políticamente correcto) y cuyo título original en alemán vendría a ser el que al principio se cita: el miedo devora el alma.

La línea que se traza entre estas dos películas -lejanas en cuanto a ubicación geográfica y tiempo, en cuanto a iluminación y paisajes- es zigzagueante, pero continua. Con un nuevo nombre, hecho con los trazos y sonidos de un nombre griego que toma prestado de un amigo muerto (el frágil y suicida Hohanness), Stavros Topouzoglou (interpretado por Stathis Giallelis) se lanza a las calles de Nueva York a limpiar zapatos en América América. "People are waiting" grita para que los clientes avancen y paguen, porque la familia entera espera por él para hacer también el viaje. Así llegó Elia Kazan, a los cuatro años, a Estados Unidos, sobrino del Stavros de la película, como narra al principio del film: "Me llamo Elia Kazan. Soy griego de sangre, turco de nacimiento y americano porque mi tío hizo un viaje".

\section{Primera peregrinación.}

Stavros ha vivido el comienzo de la movilización turca contra los armenios hacia 1896, ha visto el asesinato de su amigo armenio, Vartan (Frank Wolf), ha atravesado las montañas hasta llegar a Constantinopla y en ese trayecto lo han intentado asesinar, le han robado, golpeado, apresado y ha aprendido a matar, a sentir miedo y defenderse para salvar la piel y no balar -como le indicó su abuela-, a borrar la sonrisa de su rostro. Ya en Constantinopla se hace "hamal" (como una mula de carga), lo dan por muerto y finalmente se compromete con una joven cándida, buena y millonaria, Thomna (Linda Marsh). Durante todo este viaje hacia cierta forma de corrupción, Stavros es sostenido únicamente por la frase "América América", ese eco permanente que deviene en plegaria, en repetitivo deseo erótico que, en efecto, termina materializándose a través de la sexualidad: Stavros consigue hacer el viaje gracias al dinero que recibe de una mujer madura y casada, la señora Kebabian (Catherine Balfour), que lo convierte en su fugaz amante, un amante "pasajero" en el barco.

Como dice Florence Colombani en su libro Elia Kazan, una América del caos, Stavros pasará de familia en familia sin lograr jamás pertenecer a ninguna, convirtiéndose en un hombre al que la idea obsesiva de América corrompe profundamente. Un viaje que además, subraya la autora, muestra una Anatolia que representa la indigencia y una América que se erige como la tierra del materialismo triunfante. Del libro podemos enumerar conceptos que definen el ambiente de América América y de su Ulises: deseo y búsqueda; aislado, elegido, maldito; exiliado, en otro lugar, americano; 
traicionarse, grandeza amarga, madurez; el viaje como redención, América como redentora; el viaje como corrupción y América como corruptora.

Al final de la película vemos a Stavros lanzando una moneda al aire con una recuperada sonrisa irónica, lo que representa para Florence Colombani la asunción de dónde está y a qué ha venido.

\section{Segunda peregrinación: "la felicidad no siempre es divertida".}

Esta es la primera oración que leemos sobre la pantalla cuando comienza Todos nos llamamos Alí. Bajo la frase un charco en una calle nocturna. Sobre texto e imagen música árabe. Corte y vemos a Emmi (Brigitte Mira), una mujer de unos sesenta años, baja y rellena, entrar mojada en un bar donde continúa la música del comienzo. ¿En qué idioma cantan? -pregunta. En árabe -le responde la encargada. En la barra hay dos hombres, uno de ellos es Alí, que por insistencia de otra mujer joven invita a Emmi a bailar. Ahí despega la relación, concentrada y dolorosa, entre el joven marroquí (interpretado por El Hedi Ben Salem) y Emmi. Desde ese comienzo la relación queda sentenciada por la claridad con la que Alí ve las cosas: "alemanes y árabes juntos no es bueno. Alemán señor, árabe perro. Marruecos es bonito, pero no hay trabajo. Aquí todo el día trabajo, con coches. Pero es bueno

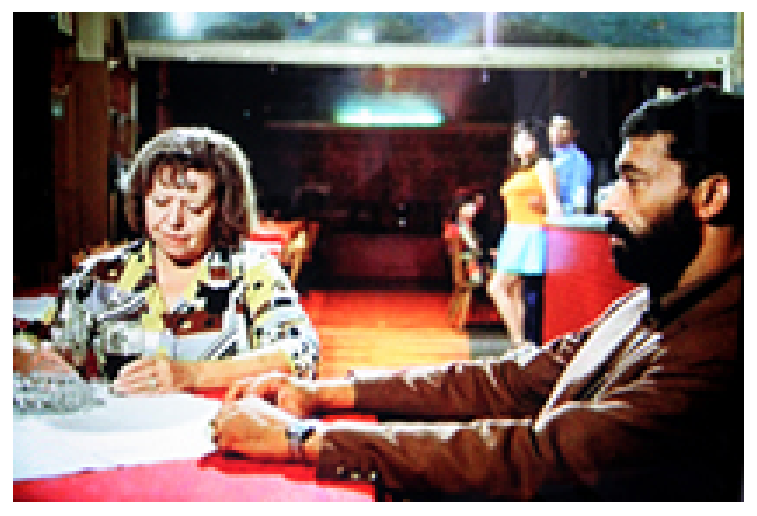

Ilustración 3 Emmi y Alí en Todos nos llamamos Alí pensar poco, si pienso mucho: lloro". Ella replica suavemente que también está todo el día en el trabajo. Los dos asumen su lugar de "otro", él extranjero, ella mujer mayor, y se enfrentan a todos: se mudan juntos y se casan. Aquí habrían acabado muchas películas, en ese arrebato de heroicidad doméstica y social. El punto final habría sido un aplauso ante el talante de ambos. Ojo: NO, por suerte no, ni tan fácil ni tan rápido, el mundo sigue su curso y nosotros encima de él, inevitable, dando vueltas dentro de las leyes de explotación y poder. No estamos ante una película de corto recorrido que se estaciona en nuestra conciencia para calmarla, al contrario, apedreaba Fassbinder: "Un cineasta puede hacer mucho. Distraer, contar historias de manera que el espectador se distraiga sin quedar atontado. Puede aclararle algunas cosas o despertarle el deseo de aclararse algunas cosas. Puede formular miedos." $\mathrm{Y}$ a esto último decidió apuntar el director alemán. La historia de Emmi y Alí resuelve rápidamente lo que pudo ser un largo trámite de valentía en otras películas, pero el miedo surge menos en el eufórico y arrebatado desplazamiento hacia la realidad que en la realidad estacionada y cotidiana: concentrada. De un lado y de otro se establecerá una tensión externa: los hijos de ella no lo aceptan, los amigos de él no lo entienden, en el trabajo de Alí se burlan de ella, en el trabajo de ella le dejan de hablar, en el edificio en el que viven los critican, los denuncian. Con un sencillo giro Fassbinder aligera de golpe esta presión exterior que los empujaba a uno contra el otro y por tanto los unía. Afuera terminan por acostumbrarse y, cómo no, aprovecharse de la situación: la fuerza de él, la ayuda de ella, el dinero de ambos. Esta holgura que les da el mundo hace que las tensiones internas afloren: lo que ayer era un pro hoy es un contra, la convivencia logra biselar las puntas que al principio eran hirientes, pero acaba también por quitarle brillo y agudeza a la imagen del otro. Él deviene, ante ella, en extranjero, y por eso le hiere en una de las capas más profundas de la cultura: el estómago; la comida pasa a ser un motivo de fractura. Ella deviene, ante él, en mujer vieja, y por eso la hiere devolviéndole su rostro 
arrugado ante el espejo: busca una amante más joven. Sin embargo siguen juntos, felices pero no contentos, frase que travestida se escucha también en Ophüls y Godard.

En ambas películas, América América y Todos nos llamamos Alí, el baile funciona como una vía de escape, una forma de canalizar la violencia, el miedo y el dolor de cada uno de los personajes. También como una manera de demostrar el amor, ese objeto tan difícil que nos arremete y que no siempre camina junto al deseo. Es territorio de paz entre la pugna inevitable de Emmi y Alí, cíclico porque reitera el amor como apoyo y ritmo. Al final del último baile de la película, Alí cae enfermo con una úlcera abierta, sangrante y recurrente. La relación del cuerpo, el más visceral y orgánico, con los dolores materiales y espirituales, con el miedo y la angustia, el deseo y el amor, es en Fassbinder una verdad: "un espíritu que, hablando existencialmente, puede moverse libremente por el aire y un cuerpo con tripas, ipufff...!"-decía.

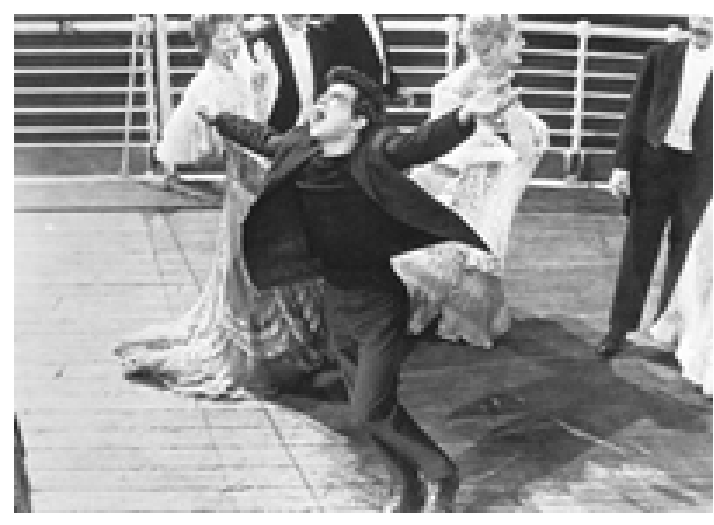

Ilustración 4 Stavros baila en la cubierta del barco en América América
Stavros se quiebra y baila también en dos momentos centrales de la película: al principio, con su amigo armenio Vartan, repitiendo con dolor y en círculo su liturgia: América América; su segundo baile lo hace sobre el barco, antes de llegar a Nueva York, cuando se lanza al centro de la cubierta a girar entre los festivos pasajeros de primera que han venido a divertirse a tercera clase. Como un animal se retuerce en el centro del ruedo, sacando su lado más oscuro, la rabia, y ahogando su lado más débil, su amigo Hohanness, que se suicida en ese instante tirándose al mar. Un baile también elegíaco por la pérdida de la inocencia, una lucha entre el cielo y el infierno en el que gana la dureza de un deseo primitivo: sobrevivir.

\section{Tercera peregrinación}

Habría estado bien incluir en el ciclo Mala noche (1985), el primer largometraje de Gus Van Sant que acaban de estrenar en Francia (sólo se había visto en festivales) y que pude ver en un cine de

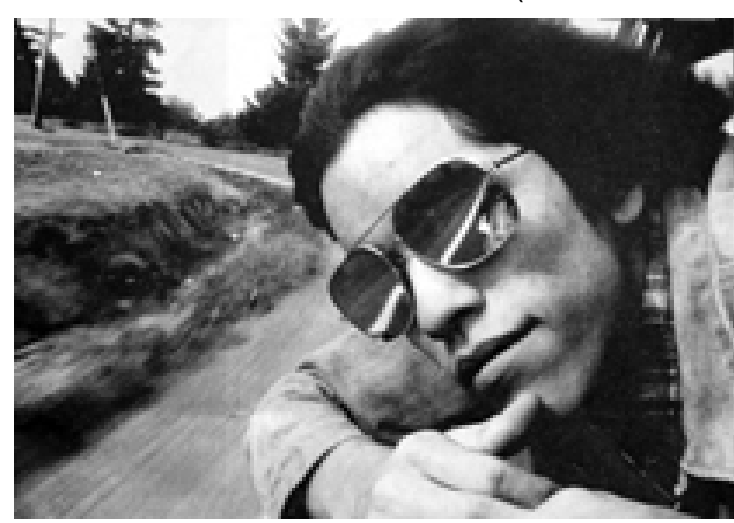

Ilustración 5 Doug Cooeyate en Mala Burdeos. La película rodea la relación amistosa, sexual y amorosa de tres jóvenes, un estadounidense de Portland y dos mexicanos clandestinos. Un viaje por carreteras y hoteles de mala muerte que, según su director, se inspiró en el Tercer hombre de Carol Reed y se alimentó visualmente de los videos ochentosos de MTV. A unas tres horas en tren de San Sebastián está Burdeos. Allí, un cine con cuatro salas, el Utopía

(place Camille Jullian), cumple la función de un festival permanente con películas de estreno y reestreno, con ciclos y conferencias, encuentros y debates. Lejos está de los diez eufóricos días de un festival de cine que cuando se retira deja a Donostia sumida en la más austera presencia fílmica, con 
un público acostumbrado a la imposibilidad de ver versiones originales subtituladas -quitando una o dos excepciones cada tanto. Entonces, ¿por qué tanta gente en las colas del festival? ¿Dónde está ese público cuando comienza el ciclo Nosferatu, cada miércoles en la noche, o estrenan alguna rareza Vos?

\section{INVENTARIO B:}

¿Qué hay de nuevo, viejo? Con esta expresión sonora comenzaba uno de los grandes placeres que tenía de pequeña: sentarme a ver la televisión, las comiquitas, donde aparecían en distintos roles el pato Lucas, Porky y Bugs Bunny, el conejo de la suerte. Con la voz del cerdo tartamudo escuchaba extasiada: esoestó-esoestó- esoestó-doamigos. Corto pero afectivo prólogo para hablar de películas nuevas, en concurso o no, proyectadas en este festival: ¿qué hay de nuevo, viejo?

Un poco a sobrevuelo veo y descubro lo que para mí es reseñable. Y recuerdo a un joven periodista o acreditado que durante la lectura de los premios (a la que asistí para ver en primera persona a Jeanne Moreau, presidenta del jurado) sugirió que se premiara con la Concha de Oro -máximo galardón- alguna película de Lubitsch, otro de los grandes y certeros ciclos de este festival. Sonrisa aparte, algo se movió en los terrenos de la nueva producción.

\section{Cuarta peregrinación.}

A mi parecer destaca un cineasta marcado por una fuerza bestial para ambientar grandes producciones y lidiar con ellas: Alfonso Cuarón. De esos directores que uno tiene la esperanza de que no se dejen tragar por la gran maquinaria a la que pertenecen y por el espectáculo puro y duro, para que sigan dando al gran público algo más que efectos o cine abultado de contenidos premasticados. En el festival presentó su última película, Hijos de los hombres (Children of men), una adaptación del libro de P.D. James que transcurre en un futuro cercano, algo así como 2027, y en el que uno de los grandes problemas es la infertilidad humana por casi dos décadas. Tanto Londres como el mundo que presenta están tecnocratizados y colapsados. El paisaje es caótico, violento, convertido en una guerra de guerrillas, en espacios paranoicos en los que los extranjeros inmigrantes pasan a ser confiscados y retenidos como objetos o animales. Un futuro del aquí mismo o del quizás (parafraseando a Miguel Casado) que nos recuerda el arranque de este perturbado presente, el único que tenemos, en el que huele a transnacionalidad y transmutación tanto como a nacionalismos excluyentes, a institucionalización de utopías, a demonización de la resistencia y a resistencias que se convierten en instituciones de poder. ¿Nos suena algo? ¿Es rebuscado? Creo que no. Al final la "esperanza" en Hijos de los hombres, con un toque de romanticismo que no desprecio, está en la fertilidad de una mujer, en una venus que nos recuerda tallas redondas y primitivas, como si escondiera la consigna de "volvamos a empezar", como una alcancía que se hincha para el futuro. Pero ¿dónde y cómo acceder a él? Con mucha nostalgia, algunos de sus personajes pelean a su manera por conseguir esa esperanza futura, como los interpretados por Clive Owen, Julianne Moore y Michael Caine: el luchador que deviene en burócrata depresivo, su ex mujer que dirige la resistencia, el hombre viejo, y su mujer, aislados en una arcadia que me recordó a los lectores en el bosque de Fahrenheit 451 de Truffaut. Un detalle personal: la emoción total al escuchar en la película la canción In The Court Of The Crimson King... 
En Hijos de los hombres el miedo aflora en todas las esquinas de la metrópolis en pánico. El amor va muriendo con cada uno de los personajes que caen en un combate sin enemigo o amigo claro. Un nacimiento se convierte en un problema político y social, pero el amor no entra ahí, sino el miedo primitivo, de nuevo: sobrevivir.

\section{Quinta peregrinación.}

"!Reaccionaria! ¡Según tu esquema no importa que los pobres no tengan plata, porque total, el dinero no hace la felicidad! ¿No?" Quino en Mafalda. Palabras de Libertad.

Carlos Sorín me tiene acostumbrada a hablar de sus películas en este festival, a encantarme con ellas. Siempre son interesantes, con momentos brillantes, y escapan a la locura de producción o de tonterías que cunden por ahí. Pero esta vez no me convenció con su fórmula que mezcla documental y ficción, incluso me desagradó. Se convirtió en una de las premiadas del evento -Premio Especial del Jurado- y tuvo gran acogida por parte del público. El director se mantiene fiel a sus personajes, sus paisajes y sus andanzas un poco vagabundas, aunque esta vez cambió La Patagonia extensa por la tupida provincia de Misiones en una road movie que lo lleva hasta la capital argentina. El camino a San Diego es una historia de amor devoto, religioso, una verdadera peregrinación hacia el encuentro de un dios: Diego Armando Maradona. Pero esta vez, vuelvo con los peros, la candidez de Tati -el personaje principal que no sé si guiñaba con el nombre del creador de M. Hulot- llegaba a llenar tanto la pantalla que a mí en particular y en general: me desesperó. Pura bondad, pura inspiración, puro amor inservible de un pobre muchacho hacia un personaje que para mí representa lo más triste y patético de eso que llaman izquierda, en particular de la y-que-izquierda latinoamericana.

Hinchado, gordo, flaco, recuperado, operado, con los ojos saltones, con la sonrisa petrificada, lleno de maquillaje, relajado, con la camiseta de argentina en su mano y su corazón y su cuello, abrazado con Fidel, abrazado con Chávez, Diego Armando Maradona es una marca de ropa made in Argentina tan manida y millonaria como la marca Che Guevara, Nike o Adidas, como bien decía M.M.A. Entonces me pregunto ¿por qué seguir alimentando que la esperanza está en y el amor pueden dedicarse a personajes tan frívolos como inconsistentes? ¿Estamos acaso en una era de la política Play Movil o Fisher Price, tan ñoña e inmadura que este Pelusa es bueno porque critica a los malos? ¿Es bueno porque dice que Bush es malo? Pero si eso es obvio. ¿Qué pasa aquí?

En un contrato que huelo millonario, en la cadena Cuatro española, el señor El Pelusa se dedicó a no decir más que obviedades durante un mundial en el que tanto el equipo del contratante como el equipo del contratado no pasaron de octavos de final. Resulta que ese señor se instala en la televisión a decir que él es distinto, que no es como X ex jugador que hoy es burócrata porque él está con los jugadores, no con la institución ni con la oficialidad. ¡Es buenazo Diego Armando! Claro, hay que defender, bajo cualquier precepto, a los once o veintidós o sesenta y seis muchachos millonarios que cobran catorce y veinte pagas millonarias, aunque no encesten un gol en cancha ajena. Y si lo encestan: premio. Sin contar con las grandes marcas -que proveen tanto al señor Bush, como al señor Castro y al señor Maradona- que les pagan a los desposeídos jugadores kilos y kilos por publicidad. Solidaria posición con los chicos la del héroe mediático. 
No, no resistí al personaje de Sorín ni a esa euforia "pelúsica" que, lejos de construir una esperanza, como señaló el jurado del festival al premiarla, apunta a una desesperanza, al eterno fantasma latinoamericano que tantos europeos reivindican: esa "pobreza con dignidad" que da asco, porque la pobreza es, simplemente: una putada; aquí, allá, o donde quiera. La dignidad dejémosela a los muertos, que la pobreza es de los vivos, y eso sí que da miedo. La "anarquía de la imaginación" es lo que nos queda.

\section{Fin}

\section{Referencias}

Colombani, Florence (2004). Elia Kazan. Une Amérique du chaos. Paris : Éditions Philippe Rey.

Duras, Marguerite (2000). Escribir. Barcelona: Tusquets Editores.

Fassbinder, Rainer Werner (2002). La anarquía de la imaginación. La memoria del cine 15. Barcelona: Paidós.

Les inrockuptibles $n^{\circ}$ 567. 10/10/2006. Entretien Gus Van Sant par Patrice Blouin et Jean-Marc Lalanne

Perec, George y Bober, Robert (1994). Récits d'Ellis Island. Histoires d'errance et d'espoir. París: P.O.L. éditeur.

\section{Formato de citación}

Bonadies, Ángela (2006). Sobre dos objetos del cine: El amor y el miedo. Athenea Digital, 10, 195202. Disponible en http://antalya.uab.es/athenea/num10/BonadiesM.pdf.

Este texto está protegido por una licencia Creative Commons.
Usted es libre de copiar, distribuir y comunicar públicamente la obra bajo las
siguientes condiciones:
Reconocimiento: Debe reconocer y citar al autor original.
No comercial. No puede utilizar esta obra para fines comerciales.
Sin obras derivadas. No se puede alterar, transformar, o generar una obra
derivada a partir de esta obra.
\[ \underline{\text { Resumen de licencia }} \]
Texto completo de la licencia

